\title{
A parametric method for evaluation of resistance of swath ships
}

\author{
Jan P. Michalski, \\ Gdańsk University of Technology \\ Polish Naval University
}

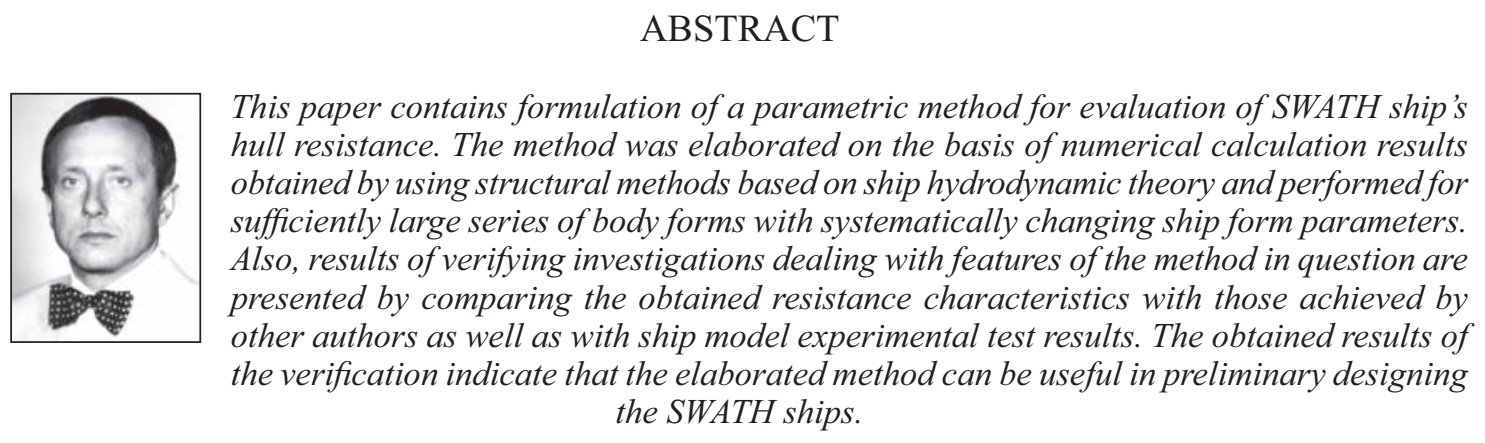

Keywords: SWATH ships design method, SWATH ships resistance evaluation method.

\section{INTRODUCTION}

The problem of ship hull resistance evaluation by using structural models based on ship hydrodynamic theory belongs to the specially difficult application tasks in shipbuilding, that results from highly complex mathematical relations describing the interaction mechanism of moving ship and surrounding water. Such calculations are performed with the use of computer methods such as e.g. the commercial software SHIPFLOW $[1,2]$ or those elaborated on the basis of own numerical algorithms, e.g. $[3,4,5,6]$, which require a large outlay of numerical calculations [7], and whose results are loaded by a low numerical stability and reliability [8]. Moreover the methods require a large labour outlay for preparation of an appropriate set of input data for realization of the calculations, mainly the data describing ship body form geometry and water region surrounding the hull.

Predictions of hull resistance characteristics obtained from structural methods are still less reliable and accurate than those resulting from experimental tests of geometrically similar hull models. The theoretical methods find their application in research and study projects to get ship resistance predictions in preliminary design stage, whose results are then verified by means of model tests in further design stage.

The acronym SWATH (Small Water-plane Area Twin Hull) stands for an innovative concept of ship of a specific configuration: its hull consists of two parts distant to each other and formed in such a way as to obtain the ratio of design waterplane area and hull volumetric displacement much smaller than that in the case of single hull ships or classical catamarans. The
SWATH ship hull consists of two slender lower hulls (submerged floats) of an elongated spindle-like form, which support deck's box platform by means of one or two slim upper hulls (columns) on each side of ship plane of symmetry, as shown in Fig. 1. On the upper deck a superstructure of a size and arrangement suitable to a given ship operational function, is usually provided. Value of design ship draught should ensure an appropriate draught of floats, low design water-plane area and appropriate clearance between water level and lower deck plating.

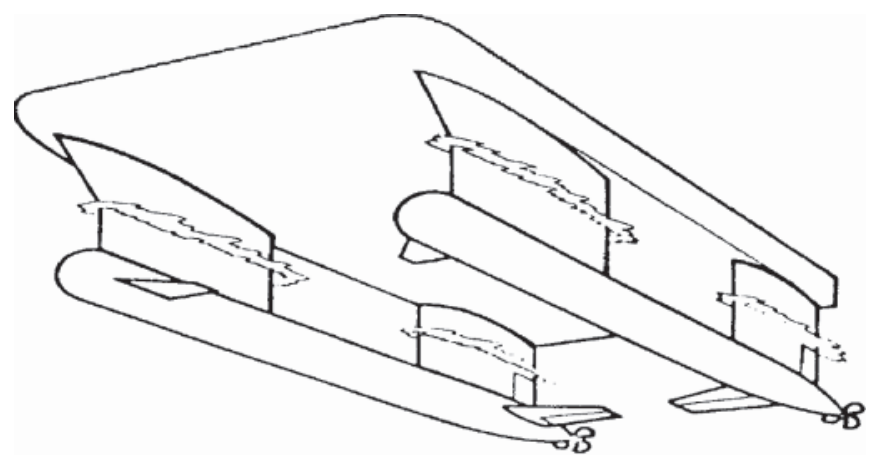

Fig. 1. Draft configuration of underwater part of SWATH ship hull.

Both the ratios of main dimensions and body form configuration of SWATH ships much differ from corresponding parameters of single-hull ships, that results in many consequences in the form of various technical features, hydrodynamic, strength and functional qualities. It concerns e.g. relations between ship main dimensions and its resistance characteristics or seakeeping qualities. Today knowledge on the 
relations is rather modest. Any extrapolation of the gathered knowledge on classical single-hull ships to SWATH ships is not reasonable as it leads to erroneous estimations rather not useful in design practice.

From practical experience has been gained so far it results that in the case when realization of ship operational function requires such its features as:

+ good seakeeping qualities

+ good resistance characteristics at high speed

+ good stability and unsinkability qualities

+ large loading space on broad deck

- then twin hull ships of small water plane area can be an interesting alternative, competitive to ships of classical body form.

In this paper is presented a parametric method for preliminary evaluation of hull resistance of SWATH ships on the basis of limited set of main design parameters of body form configuration, which is useful especially in early design stages or for carrying out design research and study work aimed at optimization of ship design solutions in a given sense. Detail results of the research on formulation of the method in question together with results of accuracy estimation of the obtained approximating relationships and description of detail assumptions of the method are published in [9].

The presented parametric method is characterized by a simpler structure of its mathematical model and is much simpler in use than the structural methods having computational algorithms based on ship hydrodynamic theory. Also, results of verifying investigations dealing with prediction features of the method in question are presented by comparing the obtained resistance characteristics with those achieved by other authors as well as with ship model experimental test results. The results show that the method in question can be deemed a useful tool in preliminary design stage of SWATH ships.

\section{AIM AND RANGE OF APPLICABILITY OF THE METHOD}

The method in question has to serve for predicting hull resistance characteristics of SWATH ships. Its mathematical model, applicability range and results of research on its predicting features are presented by comparing them with results obtained both from structural methods and experimental model tests.

The set of 1215 discrete values of wave and viscosity resistance was determined by means of structural methods for the elaborated series of 243 ship body forms of systematically changing parameters and 5 values of Froude number. For elaboration of the parametric method in question a non linear approximation of the set of discrete values obtained from computer simulations of resistance for the designed body form series, was performed.

The range of applicability of the method covers the hulls and speeds determined by the set of allowable values of the design parameters $\bar{x}(\mathrm{x} 1, \mathrm{x} 2, \mathrm{x} 3, \mathrm{x} 4, \mathrm{x} 5, \mathrm{x} 6)$, where:

- $\mathrm{x}_{1}=\mathrm{L} / \mathrm{D}_{\mathrm{p}} \in(8 \div 16)$ - lower hull slenderness

- $\mathrm{x}_{2}=\mathrm{L}_{\mathrm{k}}^{\mathrm{p}} / \mathrm{L}_{\mathrm{p}}^{\mathrm{p}} \in(0.7 \div 0.9)$ - upper hull length

- $\mathrm{x}_{3}=\mathrm{B}_{\mathrm{k}} / \mathrm{D}_{\mathrm{p}} \in(0.4 \div 0.6)$ - breadth of columns

- $\mathrm{x}_{4}=\mathrm{L}_{\mathrm{p}}^{\mathrm{k}} / \mathrm{Y}_{\mathrm{p}}^{\mathrm{p}} \in(2 \div 4)$ - dimensionless spacing of the hulls

- $\mathrm{x}_{5}=\varphi \in(0.8 \div 0.9)$ - block coefficient of lower hulls (floats)

- $\mathrm{x}_{6}=\mathrm{Fn} \in(0.3 \div 0.5)$ - Froude number related to float length.

The cylindrical coefficient $\varphi$ stands for the ratio of the float volume $\mathrm{V}_{\mathrm{p}}$ and the volume of equivalent circular cylinder circumscribed on it:

$$
\varphi=\frac{\mathrm{V}_{\mathrm{p}}}{\mathrm{L}_{\mathrm{p}} \frac{\pi \cdot \mathrm{D}_{\mathrm{p}}^{2}}{4}}
$$

The symbols of important form parameters of underwater part of ship hull are shown in Fig. 2.
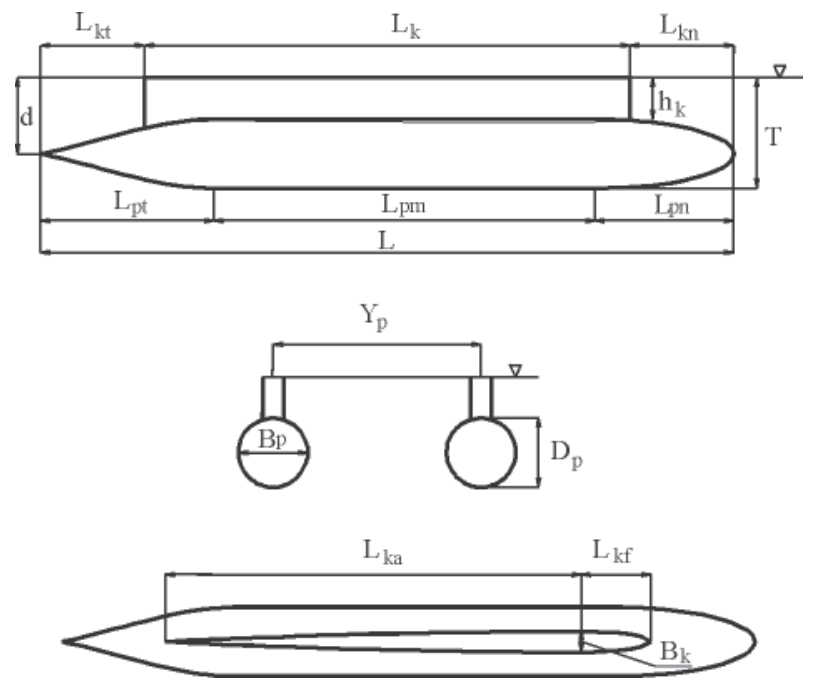

Fig. 2. Identification of form parameter s of single-column configuration of underwater part of hull of SWATH ship

The remaining parameters of the computational model such as the water density $\rho$, gravity acceleration g, dynamic viscosity coefficient $\mu$, constitute components of the vector of constant values, $\overline{\mathrm{c}}$.

\section{DESCRIPTION OF THE METHOD}

The main element of the method are the analytical mathematical relations obtained by means of approximation procedure, which associate predicted value of hull resistance with the ship design parameters $\bar{x}$, i.e.: its geometrical dimensions, speed as well as important parameters included in the vector of constants, $\bar{c}$.

In the method the superposition principle was applied - the total hull resistance $\mathrm{R}_{\mathrm{t}}$ was expressed as the sum of the wave resistance $R_{w}$ and the viscosity resistance $R_{y}$ (the remaining components of hull resistance, presented in [9] were omitted in this work as being less important). Therefore the initial relation is expressed in the classical structure form as follows:

$$
\begin{gathered}
R_{t}(\bar{x}, \bar{c})=R_{w}(\bar{x}, \bar{c})+R_{V}(\bar{x}, \bar{c})= \\
=\frac{1}{2}\left[c_{w}(\bar{x}, \bar{c})+c_{v}(\bar{x}, \bar{c})\right] \cdot \rho \cdot v^{2} \cdot \Omega(\bar{x})
\end{gathered}
$$

The characteristics of resistance coefficients are related to the wetted surface area of underwater part of ship hull, $\Omega(\bar{x})$, which is consisted of the surfaces of upper hull sides, $\Omega_{\mathrm{k}}$, and the surfaces of lower hulls (floats), $\Omega_{\mathrm{p}}$, lessened by the area of contact (penetration) surfaces of lower and upper hulls:

$$
\begin{gathered}
\Omega(\overline{\mathrm{x}})=\Omega_{\mathrm{p}}\left(\mathrm{L}_{\mathrm{p}}, \mathrm{D}_{\mathrm{p}}, \varphi, \alpha_{\mathrm{k}}\right)+\Omega_{\mathrm{k}}\left(\mathrm{L}_{\mathrm{k}}, \mathrm{B}_{\mathrm{k}}, \mathrm{T}_{\mathrm{k}}\right)= \\
=2 \cdot\left(\pi \cdot \mathrm{L}_{\mathrm{p}} \cdot \mathrm{D}_{\mathrm{p}} \cdot \varphi^{\mathrm{c}_{0}}-\mathrm{L}_{\mathrm{k}} \cdot \mathrm{B}_{\mathrm{k}} \cdot \alpha_{\mathrm{k}}^{\mathrm{c}_{1}}\right)+2 \cdot \mathrm{L}_{\mathrm{k}} \cdot \mathrm{T}_{\mathrm{k}} \cdot \mathrm{B}_{\mathrm{k}}{ }^{\mathrm{c}_{2}}
\end{gathered}
$$

The parameter $\alpha_{k}$ which appears in the term correcting the surface area of the floats stands for the column water-plane coefficient whose value can be preliminarily assumed to be $\alpha_{k}=2 / 3$. The determined structural constants in the formula expressing the wetted hull surface area are given in Tab. 1. 
Tab. 1. The structural constants in the formula (3) for wetted surface area of SWATH ship hull

\begin{tabular}{|c|c|c|c|}
\hline $\mathbf{i}=$ & 0 & 1 & 2 \\
\hline $\mathbf{C}_{\mathbf{i}}$ & 0.66666 & 1.50 & 0.002 \\
\hline
\end{tabular}

\section{Viscosity resistance characteristics}

As values of Reynolds numbers concerning flow around upper and lower hulls (floats) are very different the total viscosity resistance is given as the sum of the viscosity resistance of upper and lower hulls:

$$
\begin{gathered}
\mathrm{R}_{\mathrm{v}}(\overline{\mathrm{x}}, \overline{\mathrm{c}})=\mathrm{R}_{\mathrm{vp}}(\overline{\mathrm{x}}, \overline{\mathrm{c}})+\mathrm{R}_{\mathrm{vk}}(\overline{\mathrm{x}}, \overline{\mathrm{c}})= \\
=\frac{1}{2} \rho \cdot \mathrm{v}^{2} \cdot\left[\mathrm{c}_{\mathrm{vp}}(\overline{\mathrm{x}}, \overline{\mathrm{c}}) \cdot \Omega_{\mathrm{p}}(\overline{\mathrm{x}})+\mathrm{c}_{\mathrm{vk}}(\overline{\mathrm{x}}, \overline{\mathrm{c}}) \cdot \Omega_{\mathrm{k}}(\overline{\mathrm{x}})\right]
\end{gathered}
$$

Value of the viscosity resistance coefficient $c_{v}(\bar{x}, \bar{c})$ related to the total wetted surface area, depends on contribution of particular configuration elements of underwater part of ship's hull in generating the viscosity resistance, i.e.: on Reynolds number values, coefficients of form and wetted surface area of lower and upper hulls. The total effective hull's viscosity resistance coefficient related to the total wetted surface area, is expressed as follows:

$$
\begin{gathered}
\mathrm{R}_{\mathrm{v}}(\overline{\mathrm{x}}, \overline{\mathrm{c}})=\frac{1}{2} \rho \cdot \mathrm{v}^{2} \cdot \Omega(\overline{\mathrm{x}}) \cdot \mathrm{c}_{\mathrm{v}}(\overline{\mathrm{x}}, \overline{\mathrm{c}})= \\
=\frac{1}{2} \rho \cdot \mathrm{v}^{2} \cdot \Omega(\overline{\mathrm{x}}) \cdot\left[\mathrm{c}_{\mathrm{vp}}(\overline{\mathrm{x}}, \overline{\mathrm{c}}) \cdot \frac{\Omega_{\mathrm{p}}(\overline{\mathrm{x}})}{\Omega(\overline{\mathrm{x}})}+\mathrm{c}_{\mathrm{vk}}(\overline{\mathrm{x}}, \overline{\mathrm{c}}) \cdot \frac{\Omega_{\mathrm{k}}(\overline{\mathrm{x}})}{\Omega(\overline{\mathrm{x}})}\right]
\end{gathered}
$$

The resistance coefficients which appear in the formula were determined in [9] by means of the following parametric approximating formulae.

The viscosity resistance coefficient of lower hulls:

$$
\begin{gathered}
\mathrm{c}_{\mathrm{vp}}(\overline{\mathrm{x}}, \overline{\mathrm{c}})=\mathrm{c}_{\mathrm{fp}}(\overline{\mathrm{x}}, \overline{\mathrm{c}}) \cdot\left[1+\mathrm{k}_{\mathrm{p}}(\overline{\mathrm{x}})\right]=\mathrm{c}_{\mathrm{fp}}(\overline{\mathrm{x}}, \overline{\mathrm{c}}) \cdot\left[1+\mathrm{k}_{\mathrm{p}}\left(\mathrm{L}_{\mathrm{p}}, \mathrm{D}_{\mathrm{p}}\right)\right]= \\
=\frac{0.075}{\left(\log \frac{\mathrm{v} \cdot \mathrm{L}_{\mathrm{p}}}{\mu / \rho}-2\right)^{2}} \cdot\left[1+\left(\frac{\mathrm{D}_{\mathrm{p}}}{\mathrm{L}_{\mathrm{p}}}\right)^{\mathrm{c}}\right]
\end{gathered}
$$

where $c_{f p}$ concerns the lower hull and stands for the friction resistance coefficient (that of equivalent flat plate) and $k_{p}-$ for the form factor.

The viscosity resistance coefficient of columns is expressed by the formula:

$$
\begin{aligned}
\mathrm{c}_{\mathrm{vk}}(\overline{\mathrm{x}}, \overline{\mathrm{c}})= & \mathrm{c}_{\mathrm{fk}}(\overline{\mathrm{x}}, \overline{\mathrm{c}}) \cdot\left[1+\mathrm{k}_{\mathrm{k}}(\overline{\mathrm{x}})\right]=\mathrm{c}_{\mathrm{fk}}(\overline{\mathrm{x}}, \overline{\mathrm{c}}) \cdot\left[1+\mathrm{k}_{\mathrm{k}}\left(\mathrm{L}_{\mathrm{k}}, \mathrm{B}_{\mathrm{k}}, \alpha_{\mathrm{k}}\right)\right]= \\
& =\frac{0.075}{\left(\log \frac{\mathrm{v} \cdot \mathrm{L}_{\mathrm{k}}}{\mu / \rho}-2\right)^{2}} \cdot\left(\frac{3.2 \cdot \sqrt{2 \cdot \mathrm{B}_{\mathrm{k}} \cdot \mathrm{T}_{\mathrm{k}}}}{\mathrm{L}_{\mathrm{k}}}\right)^{1.43}
\end{aligned}
$$

where $c_{\mathrm{fk}}$ deals with the upper hull and stands for the friction resistance coefficient (that of equivalent flat plate) and $\mathrm{k}_{\mathrm{k}}-$ for the form factor whose value was determined with the use of the formula applied in [10].

The total viscosity resistance coefficient is determined in the form which makes it possible to sum it directly with the wave resistance coefficient:

$$
\begin{aligned}
& \mathrm{C}_{\mathrm{v}}(\overline{\mathrm{x}}, \overline{\mathrm{c}})=\mathrm{C}_{\mathrm{vp}}(\overline{\mathrm{x}}, \overline{\mathrm{c}})+\mathrm{C}_{\mathrm{vk}}(\overline{\mathrm{x}}, \overline{\mathrm{c}})=
\end{aligned}
$$

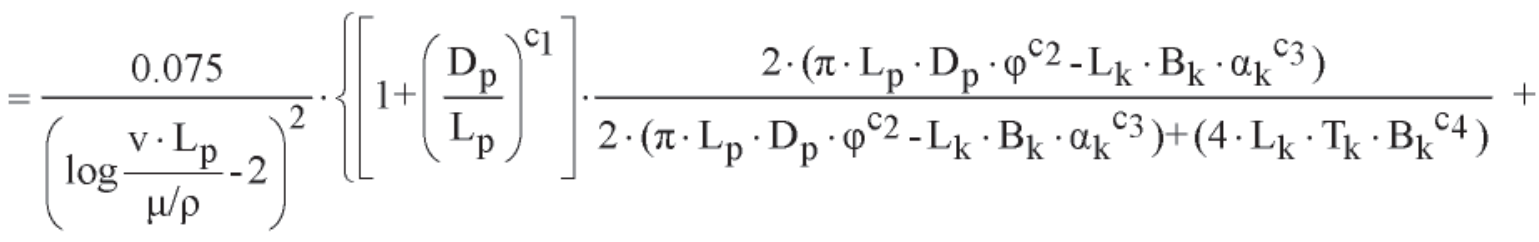

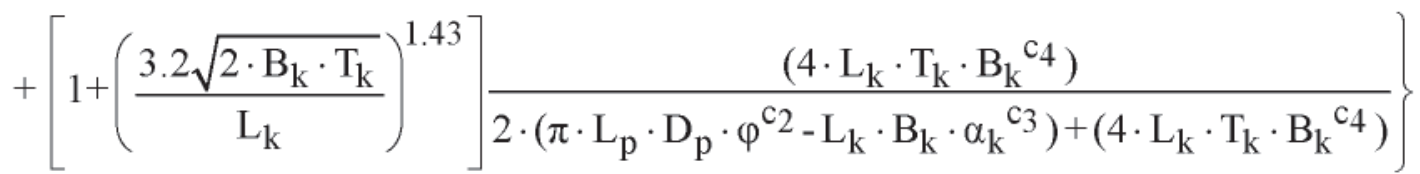


The structural constants in the formula, determined in [9], are presented in Tab. 2.

Tab. 2. The structural constants in the formula (8) for viscosity resistance characteristics of SWATH ship hull

\begin{tabular}{|c|c|c|c|c|}
\hline $\mathbf{i}=$ & 1 & 2 & 3 & 4 \\
\hline $\mathbf{C}_{\mathbf{i}}$ & 1.250 & 0.6666 & 1.50 & 0.002 \\
\hline
\end{tabular}

\section{Wave resistance characteristics}

The parametric relation which expresses generated wave resistance, covers simultaneous interaction of all hull elements:

$$
\mathrm{R}_{\mathrm{W}}(\overline{\mathrm{x}})=\frac{1}{2} \mathrm{C}_{\mathrm{W}}(\overline{\mathrm{x}}) \cdot \rho \cdot \mathrm{v}^{2} \cdot \Omega(\overline{\mathrm{x}})
$$

The analytical relation determined in [9], which approximates characteristics of the wave resistance coefficient $\mathrm{Cw}(\overline{\mathrm{x}})$, is also related to the wetted hull surface area, $\Omega(\bar{x})$, defined by the formula. The relation most accurately approximated - in the sense of the method of minimization of sum of squares of deviations - the set of discrete values to be approximated, determined by using structural methods.

The best approximating relation expressed by a combination of elementary functions was achieved by applying the formula of the following structure:

$$
\mathrm{Cw}\left(\frac{\mathrm{D}_{\mathrm{p}}}{\mathrm{L}_{\mathrm{p}}}, \frac{\mathrm{B}_{\mathrm{k}}}{\mathrm{D}_{\mathrm{p}}}, \frac{\mathrm{L}_{\mathrm{k}}}{\mathrm{L}_{\mathrm{p}}}, \frac{\mathrm{Y}_{\mathrm{p}}}{\mathrm{L}_{\mathrm{p}}}, \varphi, \mathrm{Fn}\right)=
$$

$=C_{0,0}+C_{0,1} \cdot \frac{D_{p}}{L_{p}}+C_{0,2} \cdot\left(\frac{D_{p}}{L_{p}}\right)^{2}+C_{0,3} \cdot \varphi+C_{0,4} \cdot \varphi^{2}+C_{0,5} \cdot \frac{B_{k}}{D_{p}}+C_{0,6} \cdot\left(\frac{B_{k}}{D_{p}}\right)^{2}+C_{0,7} \cdot \frac{Y_{p}}{L_{p}}+$

$\mathrm{C}_{0,8} \cdot\left(\frac{\mathrm{Y}_{\mathrm{p}}}{\mathrm{L}_{\mathrm{p}}}\right)^{2}+\mathrm{C}_{0,9} \cdot \frac{\mathrm{L}_{\mathrm{k}}}{\mathrm{L}_{\mathrm{p}}}+\mathrm{C}_{0,10} \cdot\left(\frac{\mathrm{L}_{\mathrm{k}}}{\mathrm{L}_{\mathrm{p}}}\right)^{2}+\mathrm{C}_{0,11} \cdot \frac{\mathrm{D}_{\mathrm{p}}}{\mathrm{L}_{\mathrm{p}}} \cdot \frac{\mathrm{B}_{\mathrm{k}}}{\mathrm{D}_{\mathrm{p}}} \cdot \frac{\mathrm{L}_{\mathrm{k}}}{\mathrm{L}_{\mathrm{p}}}+\mathrm{C}_{0,12} \cdot\left(\frac{\mathrm{D}_{\mathrm{p}}}{\mathrm{L}_{\mathrm{p}}}\right)^{2} \cdot\left(\frac{\mathrm{B}_{\mathrm{k}}}{\mathrm{D}_{\mathrm{p}}}\right) \cdot\left(\frac{\mathrm{L}_{\mathrm{k}}}{\mathrm{L}_{\mathrm{p}}}\right)+$

$+\left[\mathrm{C}_{1,0}+\mathrm{C}_{1,1} \cdot \frac{\mathrm{D}_{\mathrm{p}}}{\mathrm{L}_{\mathrm{p}}}+\mathrm{C}_{1,2} \cdot\left(\frac{\mathrm{D}_{\mathrm{p}}}{\mathrm{L}_{\mathrm{p}}}\right)^{2}+\mathrm{C}_{1,3} \cdot \varphi+\mathrm{C}_{1,4} \cdot \varphi^{2}+\mathrm{C}_{1,5} \cdot \frac{\mathrm{B}_{\mathrm{k}}}{\mathrm{D}_{\mathrm{p}}}+\mathrm{C}_{1,6} \cdot\left(\frac{\mathrm{B}_{\mathrm{k}}}{\mathrm{D}_{\mathrm{p}}}\right)^{2}+\mathrm{C}_{1,7} \cdot \frac{\mathrm{Y}_{\mathrm{p}}}{\mathrm{L}_{\mathrm{p}}}+\right.$

$\left.C_{1,8} \cdot\left(\frac{Y_{p}}{L_{p}}\right)^{2}+C_{1,9} \cdot \frac{L_{k}}{L_{p}}+C_{1,10} \cdot\left(\frac{L_{k}}{L_{p}}\right)^{2}+C_{1,11} \cdot \frac{D_{p}}{L_{p}} \cdot \frac{B_{k}}{D_{p}} \cdot \frac{L_{k}}{L_{p}}+C_{1,12} \cdot\left(\frac{D_{p}}{L_{p}}\right) \cdot\left(\frac{B_{k}}{D_{p}}\right)^{2} \cdot\left(\frac{L_{k}}{L_{p}}\right)\right] \cdot F n+$

$$
\left[\mathrm{C}_{2,0}+\mathrm{C}_{2,1} \cdot \frac{\mathrm{D}_{\mathrm{p}}}{\mathrm{L}_{\mathrm{p}}}+\mathrm{C}_{2,2} \cdot\left(\frac{\mathrm{D}_{\mathrm{p}}}{\mathrm{L}_{\mathrm{p}}}\right)^{2}+\mathrm{C}_{2,3} \cdot \varphi+\mathrm{C}_{2,4} \cdot \varphi^{2}+\mathrm{C}_{2,5} \cdot \frac{\mathrm{B}_{\mathrm{k}}}{\mathrm{D}_{\mathrm{p}}}+\mathrm{C}_{2,6} \cdot\left(\frac{\mathrm{B}_{\mathrm{k}}}{\mathrm{D}_{\mathrm{p}}}\right)^{2}+\mathrm{C}_{2,7} \cdot \frac{\mathrm{Y}_{\mathrm{p}}}{\mathrm{L}_{\mathrm{p}}}+\right.
$$

$\left.\mathrm{C}_{2,8} \cdot\left(\frac{\mathrm{Y}_{\mathrm{p}}}{\mathrm{L}_{\mathrm{p}}}\right)^{2}+\mathrm{C}_{2,9} \cdot \frac{\mathrm{L}_{\mathrm{k}}}{\mathrm{L}_{\mathrm{p}}}+\mathrm{C}_{2,10} \cdot\left(\frac{\mathrm{L}_{\mathrm{k}}}{\mathrm{L}_{\mathrm{p}}}\right)^{2}+\mathrm{C}_{2,11} \cdot \frac{\mathrm{D}_{\mathrm{p}}}{\mathrm{L}_{\mathrm{p}}} \frac{\mathrm{B}_{\mathrm{k}}}{\mathrm{D}_{\mathrm{p}}} \frac{\mathrm{L}_{\mathrm{k}}}{\mathrm{L}_{\mathrm{p}}}+\mathrm{C}_{2,12} \cdot\left(\frac{\mathrm{D}_{\mathrm{p}}}{\mathrm{L}_{\mathrm{p}}}\right) \cdot\left(\frac{\mathrm{B}_{\mathrm{k}}}{\mathrm{D}_{\mathrm{p}}}\right) \cdot\left(\frac{\mathrm{L}_{\mathrm{k}}}{\mathrm{L}_{\mathrm{p}}}\right)^{2}\right] \cdot \mathrm{Fn}^{2}+$

$$
\left[\mathrm{C}_{3,0}+\mathrm{C}_{3,1} \cdot \frac{\mathrm{D}_{\mathrm{p}}}{\mathrm{L}_{\mathrm{p}}}+\mathrm{C}_{3,2} \cdot\left(\frac{\mathrm{D}_{\mathrm{p}}}{\mathrm{L}_{\mathrm{p}}}\right)^{2}+\mathrm{C}_{3,3} \cdot \varphi+\mathrm{C}_{3,4} \cdot \varphi^{2}+\mathrm{C}_{3,5} \cdot \frac{\mathrm{B}_{\mathrm{k}}}{\mathrm{D}_{\mathrm{p}}}+\mathrm{C}_{3,6} \cdot\left(\frac{\mathrm{B}_{\mathrm{k}}}{\mathrm{D}_{\mathrm{p}}}\right)^{2}+\mathrm{C}_{3,7} \cdot \frac{\mathrm{Y}_{\mathrm{p}}}{\mathrm{L}_{\mathrm{p}}}+\right.
$$

$\left.\mathrm{C}_{3,8} \cdot\left(\frac{\mathrm{Y}_{\mathrm{p}}}{\mathrm{L}_{\mathrm{p}}}\right)^{2}+\mathrm{C}_{3,9} \cdot \frac{\mathrm{L}_{\mathrm{k}}}{\mathrm{L}_{\mathrm{p}}}+\mathrm{C}_{3,10} \cdot\left(\frac{\mathrm{L}_{\mathrm{k}}}{\mathrm{L}_{\mathrm{p}}}\right)^{2}+\mathrm{C}_{3,11} \cdot \frac{\mathrm{D}_{\mathrm{p}}}{\mathrm{L}_{\mathrm{p}}} \cdot \frac{\mathrm{B}_{\mathrm{k}}}{\mathrm{D}_{\mathrm{p}}} \cdot \frac{\mathrm{L}_{\mathrm{k}}}{\mathrm{L}_{\mathrm{p}}}+\mathrm{C}_{3,12} \cdot\left(\frac{\mathrm{D}_{\mathrm{p}}}{\mathrm{L}_{\mathrm{p}}}\right)^{2} \cdot\left(\frac{\mathrm{B}_{\mathrm{k}}}{\mathrm{D}_{\mathrm{p}}}\right)^{2} \cdot\left(\frac{\mathrm{L}_{\mathrm{k}}}{\mathrm{L}_{\mathrm{p}}}\right)^{2}\right] \cdot \mathrm{Fn}^{3}$ 
The structural constants which appear in the relation describing the hull wave resistance characteristics are presented in Tab. 3.

Tab. 3. The structural constants in the formula (10) for wave resistance coefficient characteristics of SWATH ship hull

\begin{tabular}{|c|c|c|c|c|c|}
\hline \multicolumn{2}{|c|}{} & $\mathbf{i}=\mathbf{0}$ & $\mathbf{i}=\mathbf{1}$ & $\mathbf{I}=\mathbf{2}$ & $\mathbf{i}=\mathbf{3}$ \\
\hline $\mathbf{C}_{\mathbf{i}, \mathbf{0}}$ & $\mathbf{j}=\mathbf{0}$ & -12.1397304 & 92.9980695 & -233.111006 & 191.37337 \\
\hline $\mathbf{C}_{\mathbf{i}, 1}$ & $\mathbf{j}=\mathbf{1}$ & -1.04586444 & 6.80487275 & -18.1580215 & 15.9779735 \\
\hline $\mathbf{C}_{\mathbf{i}, 2}$ & $\mathbf{j}=\mathbf{2}$ & 3.55241531 & -29.5798224 & 88.3886875 & -77.6752057 \\
\hline $\mathbf{C}_{\mathbf{i}, 3}$ & $\mathbf{j}=\mathbf{3}$ & 31.0710348 & -238.120645 & 598.284408 & -492.059972 \\
\hline $\mathbf{C}_{\mathbf{i}, 4}$ & $\mathbf{j}=\mathbf{4}$ & -19.1679792 & 147.631585 & -372.719428 & 307.847798 \\
\hline $\mathbf{C}_{\mathbf{i}, \mathbf{5}}$ & $\mathbf{j}=\mathbf{5}$ & -1.06797869 & 7.76205472 & -19.4101477 & 15.9798061 \\
\hline $\mathbf{C}_{\mathbf{i}, \mathbf{6}}$ & $\mathbf{j}=\mathbf{6}$ & 0.380383693 & -2.99449204 & 8.25988137 & -7.33575198 \\
\hline $\mathbf{C}_{\mathbf{i}, 7}$ & $\mathbf{j}=\mathbf{7}$ & -1.43530796 & 10.0595466 & -22.915595 & 16.9069877 \\
\hline $\mathbf{C}_{\mathbf{i}, 8}$ & $\mathbf{j}=\mathbf{8}$ & 0.853411164 & -5.32492704 & 10.4095064 & -6.21579753 \\
\hline $\mathbf{C}_{\mathbf{i}, 9}$ & $\mathbf{j}=\mathbf{9}$ & 0.83038227 & -6.91822075 & 18.3849983 & -16.0594273 \\
\hline $\mathbf{C}_{\mathbf{i}, 10}$ & $\mathbf{j}=\mathbf{1 0}$ & -0.72083999 & 5.99518048 & -16.053947 & 14.1285268 \\
\hline $\mathbf{C}_{\mathbf{i}, 11}$ & $\mathbf{j}=\mathbf{1 1}$ & 20.2259023 & -147.264231 & 371.04320 & -301.57430 \\
\hline $\mathbf{C}_{\mathbf{i}, 12}$ & $\mathbf{j}=\mathbf{1 2}$ & -2.51608454 & -1.20224482 & -4.0574586 & 37.0598212 \\
\hline
\end{tabular}

\section{VERIFICATION OF PREDICTING FEATURES OF THE METHOD}

A necessary condition of usefulness of the presented method for preliminary designing the SWATH ships should be positive assessment of its predicting features. The presented results of comparative analyses serve both for preliminary assessment of predicting merits of the elaborated structural methods and the simplified parametric method based on results obtained by using them. The verification consists in comparing the obtained results of wave resistance coefficient characteristics dealing with various body forms with theoretical results presented by other authors as well as those achieved experimentally from model tests.

The limited range of the performed comparative analyses as well as legitimacy of usefulness assessment of the verified methods are conditioned both by limited access to experimental results of model tests of SWATH ships and by lack of detail geometrical descriptions of the tested body forms given in available subject-matter literature sources.

The comparative analysis was performed by applying forms of resistance coefficients identical to those used in the publications from which the compared hull resistance characteristics were taken out. Therefore different forms of the resistance coefficient appear in the below presented diagrams. The axis of abscissae is scaled by means of Froude number related to lower hull length.

The wave resistance coefficient $\mathrm{Cw}$ is a dimensionless quantity defined in different ways, Rw stands for hull wave resistance, $\mathrm{r}_{\mathrm{o}}$ - water density, $v$ - ship speed, $\mathrm{S}$ - wetted surface area of hull underwater part, and V - volumetric displacement of hull underwater part. The resistance characteristics marked $\mathrm{Cw}$ on the diagram stand for the structural method results, and the curve marked $\mathrm{CwA}$ presents the characteristics obtained by means of the parametric method in question. And, the curve marked EXPER. shows the residuary resistance coefficient characteristics obtained experimentally.

\section{Comparison of hull resistance characteristics - Model 5287}

Description of selected body form parameters of SWATH ship Model 5287 as well as results of experimental model tests of resistance and results of theoretical calculation of wave resistance were published independently by Huang [11, 12], Lin [13] and Chun [14]. On the basis of the data the following body form parameters were identified:

$\mathrm{xr}=0.375$; relative run length of the float

$\mathrm{xw}=0.375$; relative middle (cylindrical) body length of the float $\mathrm{xd}=0.25$; relative entrance length of the float

$\mathrm{L}_{\mathrm{p}}=87.78 \mathrm{~m}$; length of the float

$\mathrm{D}^{\mathrm{p}}=5.49 \mathrm{~m}$; diameter of an equivalent axially cylindrical float $\mathrm{Y}_{\mathrm{P}}^{\mathrm{p}}=22.88 \mathrm{~m}$; spacing of axes of the floats

$\mathrm{L}_{\mathrm{k}}^{\mathrm{P}}=69.19 \mathrm{~m}$; aft column length

$\mathrm{L}_{\mathrm{kf}}=0.5$; relative entrance length of the aft column

$\mathrm{B}_{\mathrm{k}}=2.44 \mathrm{~m}$; breadth of the aft column

$\mathrm{T}^{\mathrm{k}}=8.53 \mathrm{~m}$; design draught of the ship

$\mathrm{D}=3906 \mathrm{t}$; displacement.

The wave resistance characteristics of the hull of Model 5287 form, shown in Fig. 3, graphically illustrate the results of the verifying calculations of the method in question.

Resistance coefficient characteristics of SWATH type M 5287

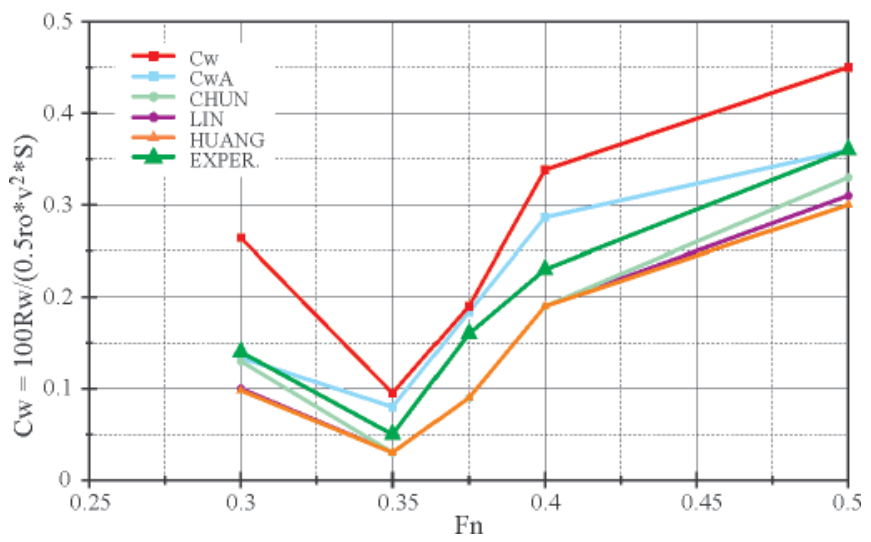

Fig. 3. Comparison of wave resistance coefficient characteristics of the hull of Model 5287 form.

The presented diagrams of the resistance coefficient characteristics make it justified to state that the results obtained by means of the structural method provide a better approximation of residuary resistance than those taken from the subject-matter literature sources $[11,12,13,14]$. For the extreme values of the considered speed range the results achieved from the parametric method are somewhat worse than those obtained from the remaining methods. 
The small spacing of the floats, $r=0.26$, is characteristic for $M-5287$ body form, that significantly contributes to an interferential character of generated wave system. Moreover the geometrical description of the body form was prepared on the basis of scanty data given in [12]. Hence possible inaccuracy of geometrical representation of the body form may cause the mentioned discrepancies of the results obtained from the parametric method.

\section{Comparison of hull resistance characteristics - Model T-AGOS}

The selected body form parameters of $T$ - $A G O S$ ship together with the experimental results of model tests of its resistance and the results of theoretical calculations of its wave resistance are contained in the publications of Chun [14] and Salvesen [15]. The following main parameters of the body form were determined:

$\mathrm{xr}=0.291$; relative run length of the float

$\mathrm{xW}=0.274$; relative length of float's middle (cylindrical) part

$\mathrm{xd}=0.434$; relative entrance length of the float

$\mathrm{L}_{\mathrm{p}}=74.34 \mathrm{~m}$; length of the float

$\mathrm{D}_{\mathrm{p}}^{\mathrm{p}}=5.36 \mathrm{~m}$; diameter of the float if axially cylindrical

$\mathrm{Y}_{\mathrm{P}}^{\mathrm{p}}=23.47 \mathrm{~m}$; spacing of axes of the floats

$\mathrm{L}_{\mathrm{k}}^{\mathrm{P}}=60.80 \mathrm{~m}$; length of aft column

$\mathrm{x}_{\mathrm{k}}=8.51$; abscissa of trailing edge of aft column

$\mathrm{L}_{\mathrm{kf}}=0.774$; relative entrance length of aft column edge of attack

$\mathrm{B}_{\mathrm{k}}=2.133 \mathrm{~m}$; breadth of aft column

$\mathrm{T}=7.42 \mathrm{~m}$; design draught of the ship

$\mathrm{PZw}=2743 \mathrm{~m}^{2}$; wetted surface area

$\mathrm{D}=2968 \mathrm{t}$; displacement.

The body form $T$-AGOS is characteristic of elliptic frame cross-sections of floats. The wave resistance coefficient characteristics of the $T-A G O S$ form hull, shown in Fig. 4, graphically illustrate the performed verifying calculations of the method.

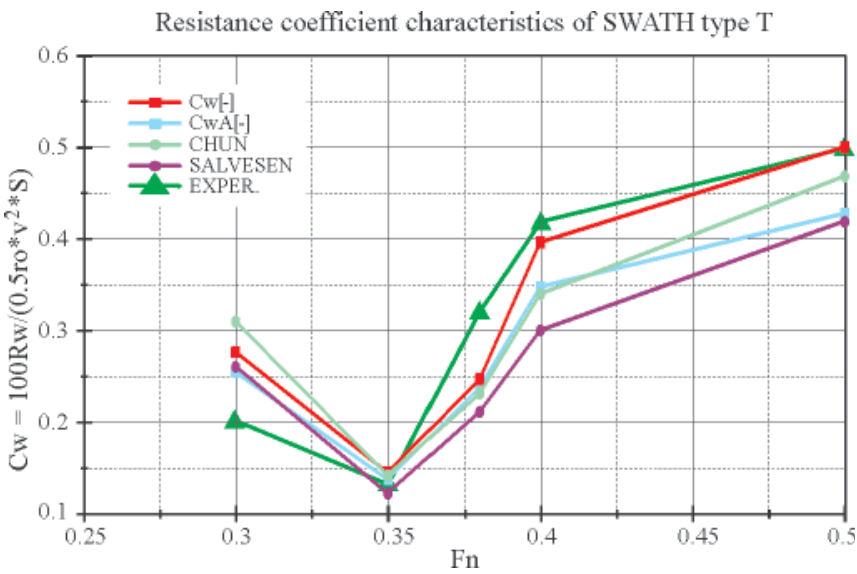

Fig. 4. Comparison of the wave resistance coefficient characteristics for the T-AGOS form hull

The comparison of the obtained results makes it justified to state that the best approximation of experimental results was achieved by means of the parametric method. The results concerning the structural method are only somewhat worse. Both the methods give better approximation of the experimental resistance characteristics than those obtained from the methods of other authors. Just this test had to constitute verification of the hypothesis that the form of the float of elliptic frame crosssections can be approximated by a distribution of hydrodynamic singularities which model an equivalent axially symmetrical float. The obtained results suggest to accept such hypothesis.

\section{Comparison of hull resistance characteristics - Model 8501}

The body form of the passenger ship $M-8501$ was investigated by Huang $[11,12]$. The publications contains some main dimensions and the distribution diagram of frame cross-section areas of body form, that made it possible to approximately reconstruct the investigated body form geometry.

The following main parameters of the body form were determined:

$\mathrm{xr}=0.25$; relative run length of the float

$\mathrm{xw}=0.6$; relative length of the float's middle (cylindrical) part

$\mathrm{xd}=0.15$; relative entrance length of the float

$\mathrm{L}_{\mathrm{p}}=28.8 \mathrm{~m}$; length of the float

$\mathrm{D}_{\mathrm{p}}^{\mathrm{p}}=2.4 \mathrm{~m}$; diameter of the float if axially cylindrical

$\mathrm{Y}_{\mathrm{p}}^{\mathrm{p}}=9.6 \mathrm{~m}$; spacing of axes of the floats

$\mathrm{L}_{\mathrm{k}}^{\mathrm{p}}=23.04 \mathrm{~m}$; length of aft column

$\mathrm{x}_{\mathrm{k}}=2.8$; abscissa of trailing edge of aft column

$z_{k}=0.3$; relative entrance length of aft column edge of attack

$\mathrm{B}_{\mathrm{k}}=1.2 \mathrm{~m}$; breadth of aft column

$\mathrm{T}=3.60 \mathrm{~m}$; design draught of the ship

$\mathrm{PZw}=477.0 \mathrm{~m}^{2} ;$ wetted surface area

$\mathrm{D}=276.9 \mathrm{t}$; displacement.

The wave resistance coefficient characteristics of the Model-8501 form hull, shown in Fig. 5, graphically illustrate the performed verifying calculations of the method.

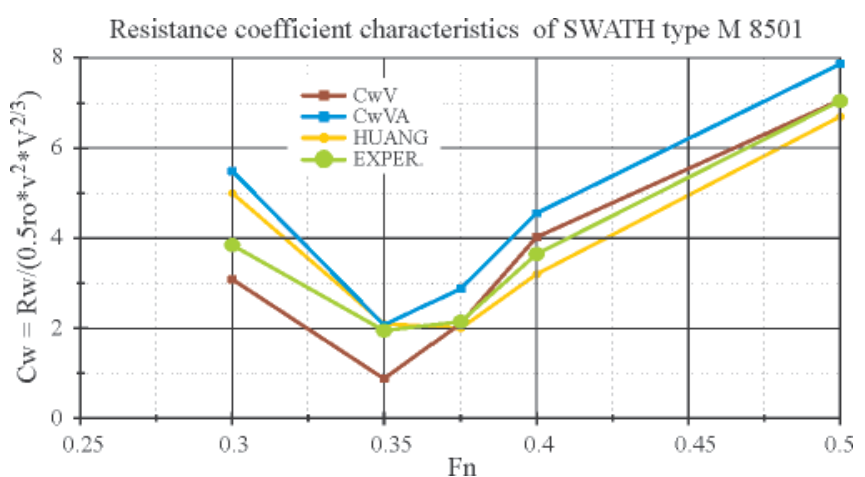

Fig. 5. Comparison of the wave resistance coefficient characteristics for the Model 8501 form hull

The resistance coefficient used on the diagram is related to the volumetric displacement of the hull underwater part, $\mathrm{V}$, in $2 / 3$ power, i.e. in the same way as defined in the referred to publications. Assessing the obtained results one can state that the elaborated structural methods as well as the parametric method for the hull resistance predicting of SWATH ships may serve as a useful tool in the preliminary design stage as this way predicted resistance correctly approximates experimental values.

\section{Comparison of hull resistance characteristics of body form series- HSVA models}

An important verifying information is obtained from comparison of the achieved theoretical results with those obtained from experimental tests of resistance of body form series performed for body forms of systematically changing parameters. Such verification makes it possible both to follow relations of values and trends of changes of resistance characteristics resulting from changes of body form geometrical parameters.

For the verification were used the results of model resistance tests of series of SWATH body forms performed in HSVA model basin, whose selected fragments were published by Schenzle [16]. On the basis of the available data the approximate parameters of the body form series were determined, that 
made it possible to perform appropriate verifying calculations. The tests of body form series, carried out in HSVA, covered about 150 configurations of SWATH hull of simplified form characterized by the following features:

$\star$ Hulls of single-column configuration

$\star$ Length of floats equal to length of columns - displaced aft by $6 \%$ against floats

$\star$ Axially symmetrical floats

$\star$ Column entrance and run lengths equal to $25 \%$ length of column

$\star$ Float entrance length equal to $80 \%$ of its run length.

The body form series which model the original HSVA forms, were obtained by systematic changing the following body form parameters:

is Cylindrical coefficient of floats - by changing their entrance length

is diameter/length ratio of floats

is breadth/length ratio of columns

is spacing/length ratio of floats (hulls)

is ratio of float axis draught and float diameter.

The approximated HSVA body form series were elaborated on the basis of the available data [16] by generating the series of body forms having geometrical parameters possibly well approximating the original parameters of the HSVA body form series. The following body form series were obtained:

$>$ of similar concept of hull configuration except of that the original forms have columns shifted aft outside region of floats, that could be only approximately taken into account in the frame of the elaborated software

$>$ of identical relative entrance and run lengths of columns and floats

$>$ of identical slenderness of floats - expressed by their diameter/length ratios

$>$ of identical maximum values of column breadth/ float diameter ratios.

The verifying calculations were performed for one determined value of draught/ diameter ratio of floats and one constant value of their spacing/length ratio. The range of investigated speeds was limited to that corresponding with Froude number values from 0.30 to 0.50 . Results of the experiments [16] are presented in the form of the residuary resistance coefficients related to displacement.

Information on form of aft and bow zones of column waterplanes, important for adequacy of comparisons, is not given in [16]. Therefore the column water-planes were arbitrarily assumed of elliptical form fore and of sharp trailing edge aft. The possible form discrepancy close to actual water-plane results in a doubt as to geometrical similarity of the compared series. The other comment associated with justification of the comparisons deals with that the experimental results were achieved by using instrumentation which made sinking the models without any trim, possible.

The results of the verifying investigations lead to the following comments:

D the HSVA body form series are characteristic by a relatively large column length/float length ratio $\mathrm{L}_{\mathrm{k}} / \mathrm{L}_{\mathrm{p}}=1$ which exceeds the assumed range of application of the parametric method, hence it was used only within the range of its possible extrapolation

- a characteristic feature of the HSVA body form series is that the columns extend aft beyond the floats, that places them outside the assumed class of allowable body forms. Therefore the HSVA body forms were so corrected as to obtain spread of the columns over the length of the floats only. The performed calculations demonstrated that
- in the case of the HSVA series - small displacements of columns against floats introduced only small changes of hull resistance ; hence the applied simplification seems to be acceptable.

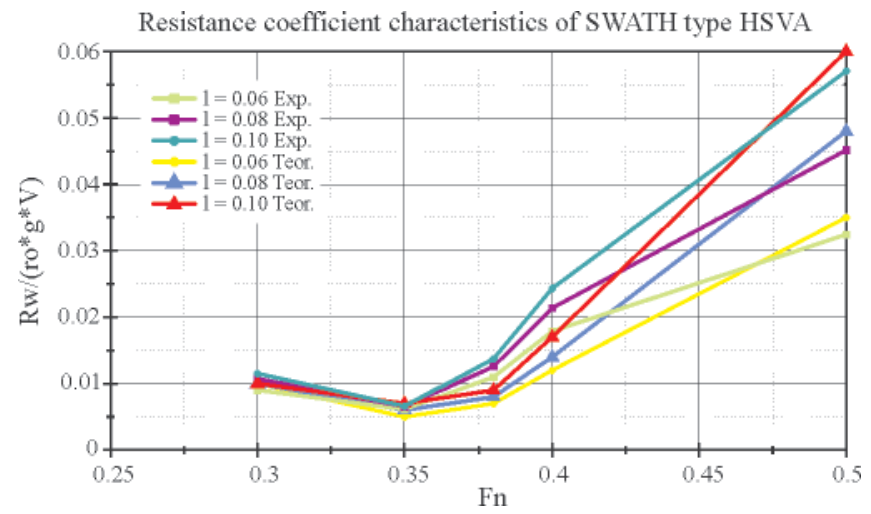

Fig. 6. Wave resistance coefficient characteristics

for HSVA series - changeable ratio $l=D p / L p$

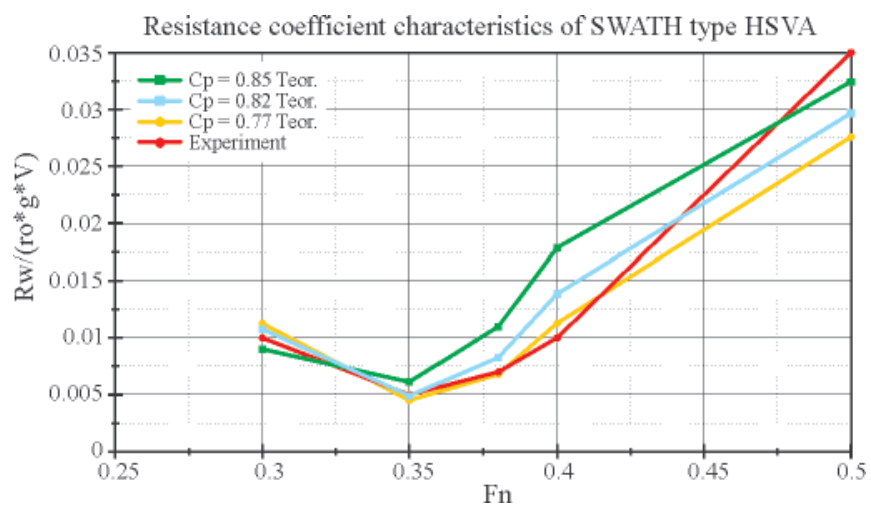

Fig. 7. Wave resistance coefficient characteristics for HSVA series - changeable coefficient $C p$.

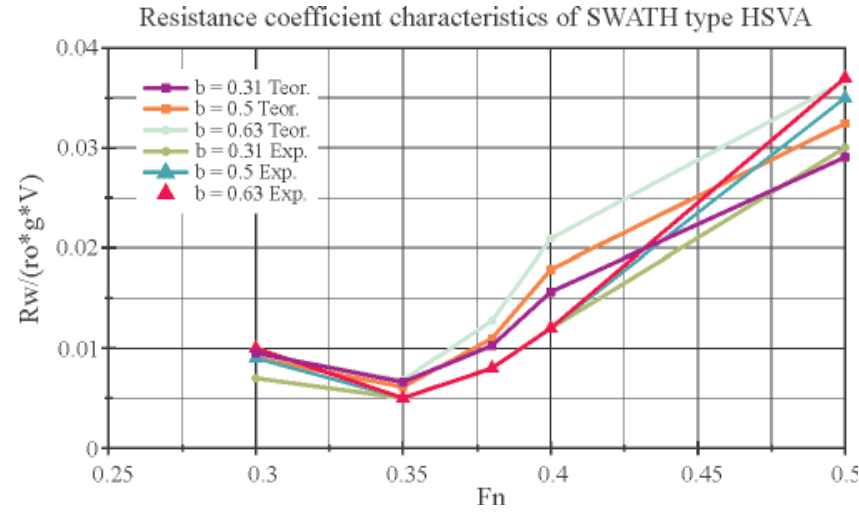

Fig. 8. Wave resistance coefficient characteristics for HSVA series - changeable ratio $b=B_{k} / D_{p}$

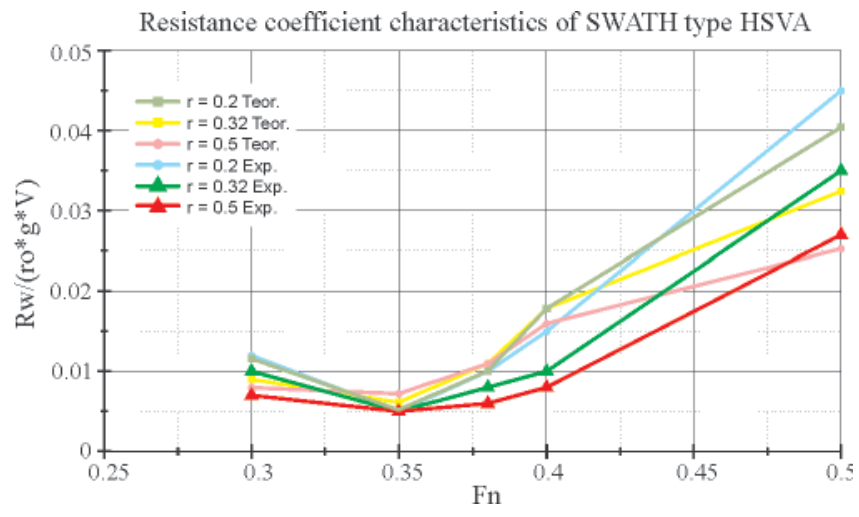

Fig. 9. Wave resistance coefficient characteristics for HSVA series - changeable ratio $r=Y_{P} / L_{p}$ 


\section{CONCLUSIONS}

The obtained results of verifying investigations make it possible to preliminarily state that both the elaborated structural methods and parametric ones dealing with hull resistance prediction of SWATH ships may serve as a useful tool in the preliminary design stage as the predicted resistance characteristics correctly approximate values of the characteristics obtained experimentally.

The thesis drawn from the preliminary investigations consists in that the elaborated parametric method - in the case of the SWATH ship hulls - provides resistance predictions of a reliability similar to that of results obtained by means of sophisticated structural methods based directly on theoretical formulations. Therefore the method may serve as a useful tool in the preliminary designing of SWATH ships.

\section{BIBLIOGRAPHY}

1. SHIPFLOW Training course. FLOWTECH International AB., Göteborg 1995

2. Larsson L.A. et al.: SHIPFLOW Theoretical Manual. FLOWTECH Int AB, Gothenburg 1994

3. Michalski J.P.: Investigation of the fitness of chosen quadratures to the calculation of wave resistance of ship. Scientific Bulletins of Gdańsk University of Technology (Zeszyty Naukowe Politechniki Gdańskiej) no. 212, Gdańsk 1974

4. Michalski J.P, Pramila A., Virtanen S.: Computer algorithm for approximate evaluation of ship body forms with minimum resistance. Nionde Nordiska Dagarna I Hallfastheslar, Oulu 1987

5. Michalski J.P., Pramila A., Virtanen S: Creation of ship body form with minimum resistance using finite element method. Proceedings of the International Conference on Numerical Methods in Engineering, NUMETA 87, Martinus Nijhoff Publ. Vol.1, Swansea 1987

6. Michalski J.P., Kozłowski K.: Elaboration of computer procedures for approximate determination of resistance of SWATH ships and assessment of their usefulness in preliminary designing (in Polish). Research Reports (Prace Badawcze) no. 618. Gdańsk University of Technology (Politechnika Gdańska), Faculty of Ocean Engineering and Ship Technology (Wydział Oceanotechniki i Okrętownictwa), Gdańsk 1995

7. Nowacki H., Michalski J., Oleksiewicz B., Bloor M., Dekanski C., Wilson M.: Computational geometry for ships. World Scientific, London 1995

8. Proceedings of the Workshop on Ship Wave Resistance Computation. Volume I. David W. Taylor Naval Ship Research and Development Center. Bethesda 1979

9. Michalski J.P.: Methods of determining resistance and generalized mass in the preliminary design stage of small waterplane area twin hull ships (in Polish). Publishing House of Gdańsk University of Technology (Wydawnictwo Politechniki Gdańskiej), Monographs 24. Gdańsk 2002

10.Min K.S.,Lee Y.W.: Design of a High-Speed 300 Passenger SWATH Ship. FAST'95: Third International Conference on Fast Sea Transportation, Travemünde 1995

11.Huang D.L., Cai Y.J.: An optimization method for form design of SWATH ships. International Shipbuilding Progress, No 414, 1991

12.Huang D.L.:A modified method for calculating the wave resistance of SWATH Ships. International Shipbuilding Progress, No 392, 1987

13.Lin W.C., Day W.G.: The still-water resistance and propulsion characteristics of small-water-plane-twin-hull (SWATH) ships. AIAA/Transactions of the Society of Naval
14.Chun H.H.: A new approach to determine the wave resistance of SWATH ships. University of Glasgow, Department of Naval Architecture and Ocean Engineering, Report no 87/46, 1987

15.Salvesen N. et al.: Hydro-numeric design of SWATH ships. Transactions SNAME, Vol.93, 1985

16.Schenzle P.: The HSVA systematic SWATH model series. FAST'95: Proceedings of the Third International Conference on Fast Sea Transportation, Lübeck - Travemünde 1995

\section{NOMENCLATURE}

\begin{tabular}{|c|c|}
\hline $\mathrm{B}_{\mathrm{k}}$ & - breadth of columns \\
\hline $\mathrm{B}_{\mathrm{p}}^{\mathrm{k}}$ & - breadth of floats \\
\hline & - vector of model constants \\
\hline $\mathrm{C}_{\mathrm{f}}$ & - friction resistance coefficient \\
\hline $\mathrm{C}_{\mathrm{fk}}^{\mathrm{f}}$ & - friction resistance coefficient of column \\
\hline $\mathrm{C}_{\mathrm{fp}}^{\mathrm{IK}}$ & - friction resistance coefficient of float \\
\hline $\mathrm{C}_{\mathrm{p}}^{\mathrm{Ip}}$ & - cylindrical coefficient of floats \\
\hline $\mathrm{C}_{\mathrm{v}}^{\mathrm{P}}$ & - viscosity resistance coefficient \\
\hline $\mathrm{C}_{\mathrm{vk}}$ & - viscosity resistance coefficient of column \\
\hline $\mathrm{C}_{\mathrm{vp}}^{\mathrm{vi}}$ & - wave resistance coefficient \\
\hline $\mathrm{D}^{\mathrm{v}}$ & - ship displacement \\
\hline $\mathrm{D}_{\mathrm{p}}$ & $\begin{array}{l}\text { - diameter of equivalent axially-symmetric cylindrical } \\
\text { float }\end{array}$ \\
\hline Fn & - Froude number \\
\hline $\mathrm{g}$ & - gravity acceleration \\
\hline $\mathrm{k}_{\mathrm{k}}$ & - column form factor \\
\hline & - float form factor \\
\hline $\mathrm{L}_{\mathrm{k}}$ & - length of columns \\
\hline $\mathrm{L}_{\mathrm{p}}^{\mathrm{k}}$ & - length of floats \\
\hline PZw & - hull wetted surface area \\
\hline $\mathrm{Rn}$ & - Reynolds number \\
\hline$R_{t}$ & - total resistance of hull \\
\hline $\mathrm{R}_{\mathrm{y}}$ & - viscosity resistance of hull \\
\hline $\mathrm{R}_{\mathrm{w}}$ & - wave resistance of hull \\
\hline $\mathrm{T}_{\mathrm{k}}$ & - draught of columns \\
\hline $\mathrm{V}$ & - ship speed \\
\hline $\mathrm{V}$ & - volumetric displacement of hull underwater part \\
\hline $\mathrm{xd}$ & - relative entrance length of floats \\
\hline $\mathrm{xr}$ & - relative run length of floats \\
\hline XW & - relative length of middle (cylindrical) part of float \\
\hline$Y_{p}$ & - spacing of axes of floats \\
\hline$\overline{\mathrm{x}}^{\mathrm{p}}$ & - vector of main ship design parameters \\
\hline $\mathrm{x}_{1}=\mathrm{L}_{\mathrm{p}} / \mathrm{D}_{\mathrm{p}}$ & - slenderness of lower hulls \\
\hline $\mathrm{x}_{2}=\mathrm{L}_{\mathrm{k}} / \mathrm{L}_{\mathrm{p}}$ & - length of upper hulls \\
\hline $\mathrm{x}_{3}=\mathrm{B}_{\mathrm{k}} / \mathrm{D}_{\mathrm{p}}$ & - breadth of columns \\
\hline $\mathrm{x}_{4}=\mathrm{L}_{\mathrm{p}}{ }^{\mathrm{P}} / \mathrm{Y}_{\mathrm{p}}^{\mathrm{p}}$ & - dimensionless spacing of hulls \\
\hline$x_{5}=\varphi$ & - block coefficient of lower hulls \\
\hline $\mathrm{x}_{6}=\mathrm{Fn}$ & - Froude number related to float length \\
\hline$\alpha_{k}$ & - water-plane coefficient of column \\
\hline$\varphi$ & - cylindrical coefficient of floats \\
\hline$\rho$ & - water density \\
\hline$\mu$ & - dynamic viscosity coefficient of water \\
\hline$\Omega$ & - area of reference surface \\
\hline$\Omega_{\mathrm{k}}$ & - area of wetted surface of upper hulls \\
\hline & - area of wetted surface of lower hulls. \\
\hline
\end{tabular}

\section{CONTACT WITH THE AUTHOR}

Assoc. Prof. Jan P. Michalski

Faculty of Ocean Engineering and Ship Technology

Gdansk University of Technology Narutowicza 11/12

80-952 Gdansk, POLAND

e-mail : janmi@pg.gda.pl 